\title{
Immunohistochemical expression of somatostatin type 2A receptor in neuroendocrine carcinoma of uterine cervix
}

\author{
Hiroshi Kajiwara $\cdot$ Kenichi Hirabayashi $\cdot$ Masaki Miyazawa $\cdot$ Naoya Nakamura \\ Takeshi Hirasawa $\cdot$ Toshinari Muramatsu $\cdot$ Mikio Mikami $\cdot$ Masanori Yasuda \\ R. Y. Osamura
}

Received: 11 June 2008 / Accepted: 7 August 2008 / Published online: 26 August 2008

(C) The Author(s) 2008. This article is published with open access at Springerlink.com

\begin{abstract}
Introduction Somatostatin and its analogues inhibit the growth of various kinds of endocrine and exocrine cells via the somatostatin receptor (SSTR). Expression of SSTR2A has been reported in many well-differentiated neuroendocrine tumors and small numbers of poorly differentiated neuroendocrine carcinomas. SSTR2A-positive neuroendocrine tumors may be treatable by SS analogues. Uterine cervical neuroendocrine carcinoma is generally associated with poor prognosis.

Materials and methods We examined the expression of SSTR2A and other neuroendocrine markers [neural cell adhesion molecule (NCAM), chromogranin A, and synaptophysin] by immunohistochemical methods in seven neuroendocrine tumors of the uterine cervix: five small cell carcinomas and two large cell neuroendocrine carcinomas.

Results SSTR2A was expressed in one small cell carcinoma and two neuroendocrine large cell carcinomas. The cell membrane of cells in these carcinomas showed strong immunohistochemical reactivity for SSTR2A. SSTR2Apositive cases are also frequently positive for the expres-
\end{abstract}

H. Kajiwara $(\varangle) \cdot$ K. Hirabayashi $\cdot$ M. Miyazawa $~$

N. Nakamura $\cdot$ R. Y. Osamura

Department of Pathology, Tokai University School of Medicine,

143 Shimokasuya, Isehara, Kanagawa 259-1193, Japan

e-mail: h-kaji@is.icc.u-tokai.ac.jp

T. Hirasawa $\cdot$ T. Muramatsu $\cdot$ M. Mikami

Department of Obstetrics and Gynecology,

Tokai University School of Medicine,

143 Shimokasuya, Isehara, Kanagawa 259-1193, Japan

M. Yasuda

Department of Pathology,

Saitama Medical University International Medical Center,

397-1 Yamane, Hidaka, Saitama 350-1298, Japan sion of chromogranin A. Treatment with SSTR2A may be effective for endocrine tumors. The results indicate the usefulness of SSTR2A analogs for the treatment of some uterine neuroendocrine carcinomas.

Keywords Somatostatin receptor2A (SSTR2A) .

Neuroendocrine tumor · Uterine cervix ·

Immunohistochemistry

\section{Introduction}

Well-differentiated neuroendocrine tumors, such as carcinoid tumors and pancreatic endocrine tumors, generally have a good prognosis. However, poorly differentiated endocrine carcinomas, such as small cell lung cancer, medullary carcinoma, and uterine neuroendocrine carcinomas have distant metastases in the liver, lung, or bone; neither chemotherapy nor irradiation therapy is very effective in treating them. Neuroendocrine carcinoma of the uterine cervix has been described as the tumor with the worst prognosis. The mean survival time for patients with this carcinoma has been reported to be 32.3 months [1].

Somatostatin has a broad spectrum of biological actions; exerts suppressive effects on multiple organs, including the brain, pituitary, gut, exocrine and endocrine pancreas, adrenals, thyroid, and kidneys; and appears to be an endogenous growth inhibitor [2].

The diverse biological effects of somatostatin are mediated by a family of $\mathrm{G}$ protein-coupled receptors [namely, somatostatin receptors (SSTRs)] that are encoded by five non-allelic genes located on separate chromosomes. The receptors can be further divided into 5 subtypes. This review focuses on the molecular pharmacology and function of these receptors, with particular emphasis on the 
ligand-binding domain, subtype-selective analogs, agonistdependent receptor regulation, desensitization responses, subtype-specific effector coupling, and the signal transduction pathways responsible for inhibiting cell secretion and cell growth or induction of apoptosis [3].

Although there have been investigations on the localization of SSTR by autoradiography, PCR, and in situ hybridization (ISH) [4-6], few studies have examined the cellular localization of the receptor subtype proteins in neuroendocrine tumors, especially in metastatic or highly malignant neuroendocrine tumors $[2,7,8]$.

Uterine cervical endocrine carcinoma is rare. Therefore, there are few reports on the expression of SSTR2A in uterine cervical endocrine carcinoma.

In the present study, we examined the expression of SSTR2A in uterine cervical neuroendocrine cancers.

\section{Materials and methods}

The majority of the specimens investigated were surgically obtained, and the findings were noted in the records of the Tokai University Hospital. The seven neuroendocrine carcinomas of uterine cervix examined included five small cell carcinomas and two large cell neuroendocrine carcinomas. Two of the former carcinomas were accompanied with squamous cell carcinoma and adenosquamous cell carcinoma. In five of all the seven cases, there was a distant metastasis and death from the disease within 2 years after the operation, except in two current cases (Table 1).

\section{Immunohistochemistry}

The tissues were fixed by immersion in $4 \%$ buffered formaldehyde and embedded in paraffin according to standard procedures. These tissues were subjected to the following studies. For immunohistochemical staining, 4$\mu \mathrm{m}$ sections were deparaffinized and rehydrated. Blocking of endogenous peroxidase was done by pretreating the sections by methanol containing $10 \% \quad \mathrm{H}_{2} \mathrm{O}_{2}$ for $30 \mathrm{~min}$. The primary antibodies that were used, the procedure for their dilution, and the method of antigen retrieval from the sections are described in Table 2. The immunohistochemical staining for SSTR2A was carried out by using the Envision/HRP kit (DAKO). The nuclei were slightly counterstained with hematoxylin. To reveal the colocalization of immunoreactive SSTR2A and other neuroendocrine markers (namely, neural cell adhesion molecule (NCAM), chromogranin A, synaptophysin), serial sections were cut, and pairs of adjacent sections were examined (Table 3).

For the positive control specimens of SSTR2A, we used normal pancreas tissues obtained by autopsy, fixed by $10 \%$ buffered formalin, and embedded in paraffin.

\section{Evaluation of immunostaining}

The results of immunostaining for SSTR2A and other neuroendocrine markers were evaluated. When less than $25 \%$ cells were positively stained, the results were classified as +; when $25-50 \%$ cells were stained positively, they were

Table 1 Profile of present cases

\begin{tabular}{llllll}
\hline Case & $\begin{array}{l}\text { Age } \\
\text { (years) }\end{array}$ & Histopathology & pTNM stage & Metastatic organs & $\begin{array}{l}\text { Outcome } \\
\text { (post-operative months) }\end{array}$ \\
\hline 1 & 73 & Small + squamous & T3aN1 & Liver, lung, brain & DOD 18M \\
2 & 23 & Small & T2aN1 & Liver, bone & DOD 11M \\
3 & 37 & Large cell neuroendocrine & T1b2N1 & Thyroid, breast, bone, peritoneum & DOD 21M \\
4 & 55 & Large cell neuroendocrine & T2aN0 & Liver, lung, bone & DOD 12M \\
5 & 51 & Small & T2bN0 & Liver, adrenal, bone, peritonrum & DOD 16M \\
6 & 56 & Small + adenosquamous & T1b1N0 & Ascites & AWD* \\
7 & 50 & Small & T3bN1MA & - & AWD $^{*}$
\end{tabular}

$D O D$ death of disease, $A W D$ alive with disease

* Postoperative observation is less than 6 months

Table 2 Primary antibodies and method of antigen retrieval

\begin{tabular}{lllll}
\hline & $\begin{array}{l}\text { Code or } \\
\text { clone }\end{array}$ & Manufacturer & Dilution & Antigen retrieval \\
\hline SSTR2A & ss-800 & Gramsch & $1: 500$ & Boil used by citrate buffer/pH 6.0 \\
NCAM & $1 \mathrm{~B} 6$ & Novo castra & $1: 50$ & Boil used by citrate buffer/pH 6.0 \\
Chromogranin A & Poly & Invitrogen & $1: 1$ & - \\
Synaptophysin & N1566 & DAKO & $1: 50$ & $1 \%$ trypsin \\
\hline
\end{tabular}


Table 3 Result of immunostaining

Positive rate of expressed neuroendocrine tumor cells, - negative, + less than $25 \%,++25-$ $50 \%,+++$ more than $50 \%$

$C G A$ chromogranin A, $S Y N$ synaptophysin

\begin{tabular}{|c|c|c|c|c|c|c|c|c|}
\hline \multirow[t]{2}{*}{ Case } & \multicolumn{4}{|c|}{ Endocrine component } & \multicolumn{4}{|c|}{ Non-endocrine components } \\
\hline & SSTR2A & NCAM & CGA & SYN & SSTR2A & NCAM & CGA & SYN \\
\hline 1 & - & - & + & +++ & - & - & - & - \\
\hline 2 & - & +++ & + & +++ & & & & \\
\hline 3 & +++ & +++ & ++ & +++ & & & & \\
\hline 4 & + & - & +++ & +++ & & & & \\
\hline 5 & - & ++ & - & + & & & & \\
\hline 6 & + & +++ & ++ & + & - & - & - & - \\
\hline 7 & - & +++ & + & ++ & & & & \\
\hline
\end{tabular}

classified as ++; and when more than $50 \%$ cells were stained positively, they were classified as +++ .

\section{Results}

Neuroendocrine carcinomas showed immunohistochemical expression of NCAM in five cases, that of chromogra$\operatorname{nin} \mathrm{A}$ in six cases, and that of synaptophysin in all the seven cases. In one of the five cases of small cell carcinoma and both the cases of large cell neuroendocrine carcinomas, positive staining for SSTR2A was observed. SSTR2A-positive cases also frequently expressed chromogranin $\mathrm{A}$. In a case where high SSTR2A expression was noted, other endocrine markers (NCAM, chromogranin A, and synaptophysin) were also frequently expressed. In the two mixed tumors comprising of small cell carcinoma and non-neuroendocrine carcinoma (squamous cell carcinoma or adenosquamous carcinoma), SSTR2A was not expressed in the non-neuroendocrine components. SSTR2A was detected on the cell membrane (Figs. 1 and 2).

\section{Discussion}

Uterine cervical neuroendocrine tumors are histopathologically classified into four groups: carcinoid tumors, atypical carcinoid tumors, small-cell carcinomas, and large-cell neuroendocrine carcinomas [9]. These tumors arise in reserve cells of the basal epithelial layer, as well as squamous cell carcinoma and adenocarcinoma. Therefore, mixed tumors of small cell carcinoma and squamous or
Fig. 1 Large-cell neuroendocrine carcinoma (case 3 ). Tumor cells are frequently positive for SSTR2A (b), chromogranin A (c) and NCAM (d)

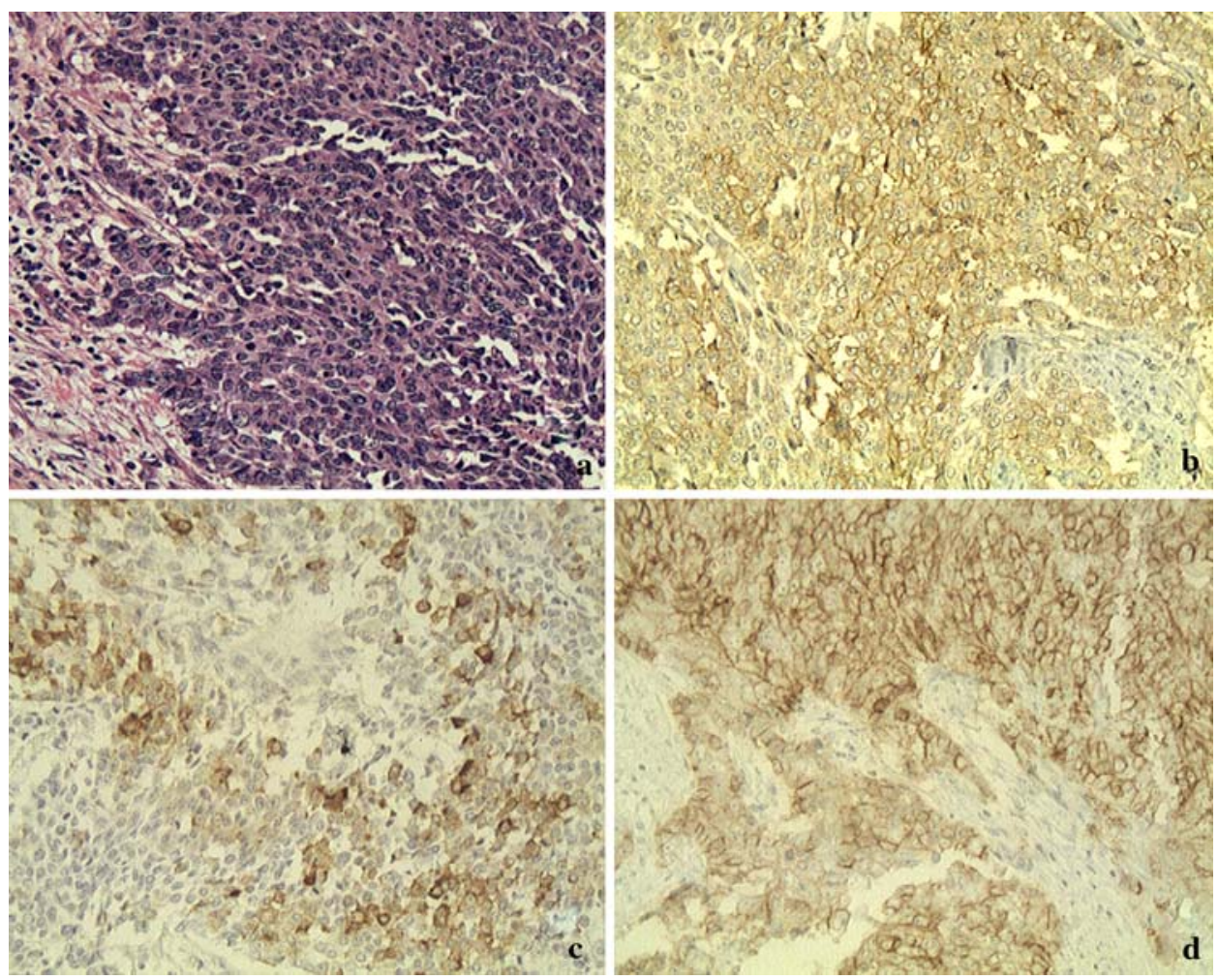


Fig. 2 Small-cell carcinoma and squamous cell carcinoma (case 6). In the small-cell carcinoma component, tumor cells are positive for SSTR2A (b), chromogranin A (c), and NCAM (d). In the squamous cell component (arrow head), tumor cells are negative for SSTR2A and NCAM
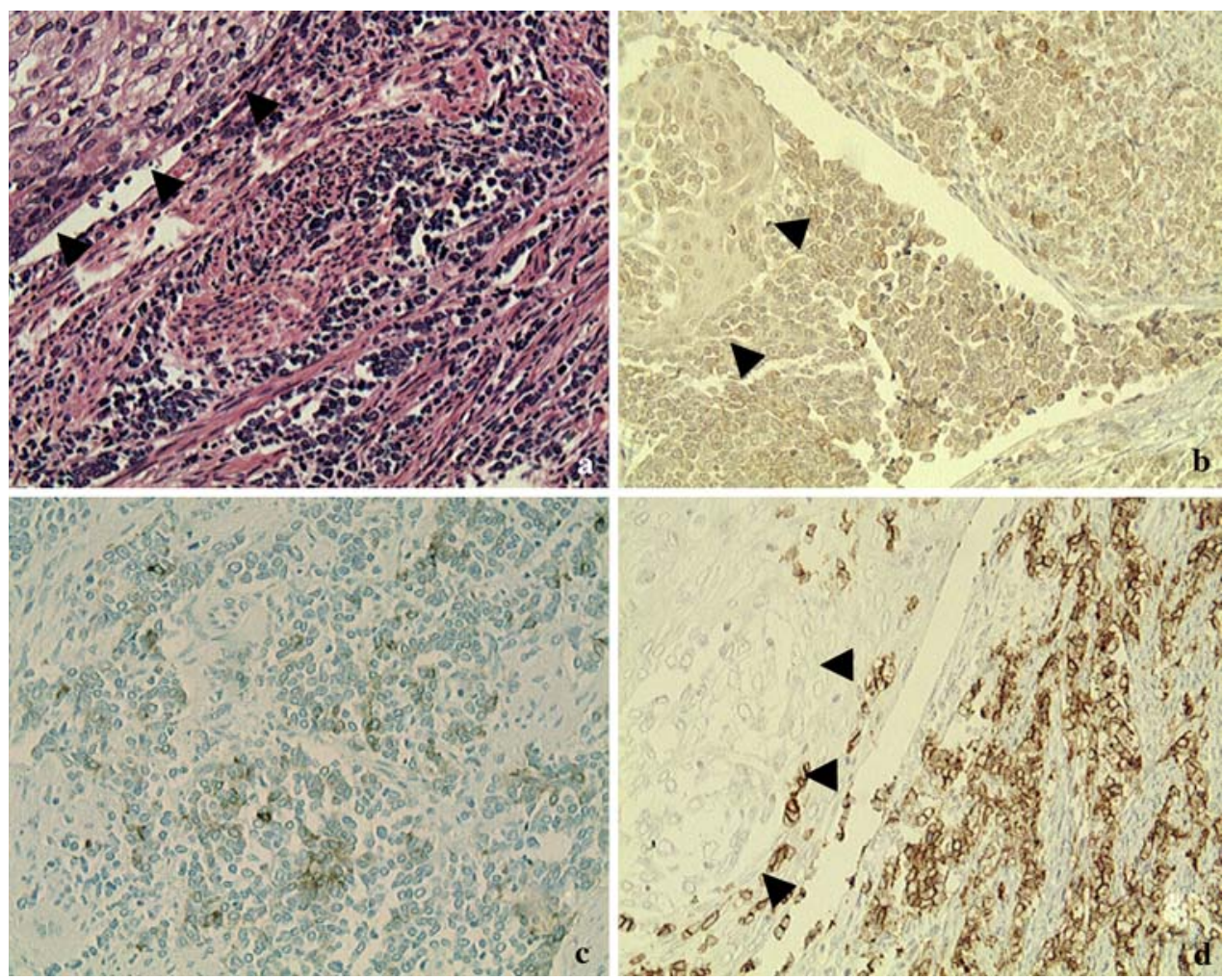

adenocarcinoma are rarely observed. Neuroendocerine carcinomas of uterine cervix have been known to detect common neuroendocrine markers (NCAM, chromogranin A and synaptophysin) [10,11].

Neuroendocrine tissues and their tumors have been found to express SSTR by SSTR autoradiography or ISH of SSTR mRNA [5, 6, 12]. Reubi et al. comprehensively investigated the expression of SSTR mRNA in human tumors by using receptor autography. By using an immunohistochemical method, Kimura et al. [2] found that SSTR is expressed in many well-differentiated neuroendocrine carcinomas and some poorly differentiated neuroendocrine carcinomas. The tumors were characterized as having receptors with a high affinity for the synthetic analogue octreotide [13]. Janson et al. [6] reported that the expression of SSTR2 mRNA detected using ISH correlates with therapeutic outcome in patients with carcinoid tumors treated with somatostatin analogs.

However, to our knowledge, there have been no immunohistochemical studies of SSTR2A in poorly differentiated neuroendocrine carcinomas of the uterine cervix. As the numbers of cases studied with the report are rather limited, therefore is should be mentioned that the current study is a pilot study and its results should be confirmed in an extended study containing larger number of cases. Our study showed that SSTR2A is the useful neuroendocrine markers, as well as NCAM, chromogranin A and synaprophysin, in the uterine cervical neuroendocrine carcinomas like other neuroendocrine tumors.
A number of somatostatin analogs have been used for the treatment of acromegaly and endocrine tumors of the gastroenteropancreatic system $[14,15]$. Most of these tumors and cell lines express SSTR2 [13, 16], and SSTR5 mRNA is also expressed in gastroenteropancreatic tumors [17]. The activation of a tyrosine phosphatase and the inhibition of calcium mobilization mediated by SSTR2 and SSTR5, respectively, could be important steps in the negative mitogenic signal induced by a somatostatin analog [17]. Janson et al. [6] compared the efficacy of the SSTR2 mRNA expression and the response to treatment with SS analog in patients with carcinoid tumors. They concluded that there was a complete agreement between the presence of SSTR2 mRNA detected using ISH and a positive therapeutic outcome. Recently, they conducted an immunohistochemical study on SSTR2 in the above tumors and obtained the same results, and concluded that immunohistochemical methods are applicable in clinical practice [15]. Although there were no cases of treatment with somatostatin analogs in the present study, we would like to refer to the possible utility of somatostatin analogs for treating not only carcinoid tumors but also malignant neuroendocrine tumors, including metastatic pheochromocytoma, neuroendocrine carcinoma, and infiltrating ganglioneuroma, for which there are no effective treatments at present. Further practical investigations of using somatostatin analogs for treating patients with such tumors should be conducted.

The prognosis of uterine cervical neuroendocrine cancers is poor, and no chemotherapy has been known to be 
effective in treating these. One study used a combined chemotherapy, including a somatostatin analog (octreotide), for treating uterine cervical atypical carcinoid tumors [18]. However, the effect has not been confirmed. Somatostatin analogs can be expected effective for SSTR2A-positive uterine cervical neuroendocrine neoplasm in future. In addition, in uterine cervix cancers of mixed histological type comprising of neuroendocrine and non-neuroendocrine components, it seemed that a combination of somatostatin analogs and conventional chemotherapy was necessary.

Open Access This article is distributed under the terms of the Creative Commons Attribution Noncommercial License which permits any noncommercial use, distribution, and reproduction in any medium, provided the original author(s) and source are credited.

\section{References}

1. Wang KL, Yang YC, Wang TY, Chen JR, Chen TC, Chen HS et al (2006) Neuroendocrine carcinoma of the uterine cervix: a clinicopathologic retrospective study of 31 cases with prognostic implications. J Chemother 18:209-216

2. Kimura N, Pilichowska M, Date F, Kimura I, Schindler M (1999) Immunohistochemical expression of somatostatin type 2A receptor in neuroendocrine tumors. Clin Cancer Res 5:3483-3487

3. Patel YC, Srikant CB (1997) Somatostatin receptors. Trends Endocrinol Metab 8:398-405. doi:10.1016/S1043-2760(97) 00168-9

4. Reubi JC, Waser B, Lamberts SW, Mengod G (1993) Somatostatin (SRIH) messenger ribonucleic acid expression in human neuroendocrine and brain tumor using in situ hybridization histochemistry: comparison with SRIH receptor content. J Clin Endocrinol Metab 76:642-647. doi:10.1210/jc.76.3.642

5. Reubi JC (1997) Relevance of somatostatin receptors and other peptide receptors in pathology. Endocr Pathol 8:11-20. doi:10. 1007/BF02739703

6. Janson ET, Gobl A, Kalkner KM, Oberg K (1996) A comparison between the efficacy of somatostatin receptor scintigraphy and that of in situ hybridization for somatostatin receptor subtype 2 messenger RNA to predict therapeutic outcome in carcinoid patients. Cancer Res 576:2561-2565

7. Reubi JC, Kappeler A, Waser B, Laissue J, Hipkin RW, Schonbrunn A (1998) Immunohistochemical localization of somatostatin receptors sst2A in human tumors. Am J Pathol 153:233-245
8. Janson ET, Stridsberg M, Gobl A, Westlin JE, Oberg K (1998) Determination of somatostatin receptor subtype 2 in carcinoid tumors by immunohistochemical investigation with somatostatin receptor subtype 2 antibodies. Cancer Res 58:2375-2378

9. Albores-Saavedra J, Gersell D, Gilks CB, Henson DE, Lindberg G, Santiago H et al (1997) Terminology of endocrine tumors of the uterine cervix: results of a workshop sponsored by the College of American Pathologists and the National Cancer Institute. Arch Pathol Lab Med 121:34-39

10. Albores-Saavedra J, Latif S, Carrick KS, Alvarado-Cabrero I, Fowler MR (2005) CD56 reactivity in small cell carcinoma of the uterine cervix. Int J Gynecol Pathol 24:113-117. doi:10.1097/ 00004347-200504000-00001

11. Sato Y, Shimamoto T, Amada S, Asada Y, Hayashi T (2003) Large cell neuroendocrine carcinoma of the uterine cervix: a clinicopathological study of six cases. Int J Gynecol Pathol 22:226230. doi:10.1097/01.PGP.0000071046.12278.D1

12. Yamada Y, Post SR, Wang K, Tager HS, Bell G, Seino S (1992) Cloning and functional characterization of a family of human and mouse somatostatin receptors expressed in brain, gastrointestinal tract, and kidney. Proc Natl Acad Sci USA 89:251-255. doi:10.1073/pnas.89.1.251

13. Reubi JC, Schaer JC, Waser B, Mengod G (1994) Expression and localization of somatostatin receptor SSTR1, SSTR2, and SSTR3 messenger RNAs in primary human tumors using in situ hybridization. Cancer Res 54:3455-3459

14. Yang IM, Woo JT, Kim SW, Kim JW, Kim YS, Choi YK (1995) Characteristics of acromegalic patients with a good response to octreotide, a somatostatin analogue. Clin Endocrinol (Oxf) 42:295-301. doi:10.1111/j.1365-2265.1995.tb01878.x

15. Nilsson O, Kolby L, Wangberg B, Wigander A, Billig H, WilliamOlsson L et al (1998) Comparative studies on the expression of somatostatin receptor subtypes, outcome of octreotide scintigraphy and response to octreotide treatment in patients with carcinoid tumours. Br J Cancer 77:632-637

16. Eden PA, Taylor JE (1993) Somatostatin receptor subtype gene expression in human and rodent tumors. Life Sci 53:85-90. doi:10.1016/0024-3205(93)90614-9

17. Buscall L, Esteve J-P, Saint-Laurent N, Bertrand V, Reisine T, O'Carroll AM et al (1995) Inhibition of cell proliferation by the somatostatin analogue RC-160 is mediated by somatostatin receptor subtypes SSTR2 and SSTR5 through different mechanisms. Proc Natl Acad Sci USA 92:1580-1584. doi:10.1073/pnas.92. 5.1580

18. Koch CA, Azumi N, Furlong MA, Jha RC, Kehoe TE, Trowbridge $\mathrm{CH}$ et al (1999) Carcinoid syndrome caused by an atypical carcinoid of the uterine cervix. J Clin Endocrinol Metab 84:4209-4213. doi: $10.1210 /$ jc.84.11.4209 